Benjamin J. M. Johnson

\title{
Reading David and Goliath in Greek and Hebrew
}

\author{
A Literary Approach \\ [David und Goliath auf Griechisch und Hebräisch lesen. Ein literarischer Ansatz.]
}

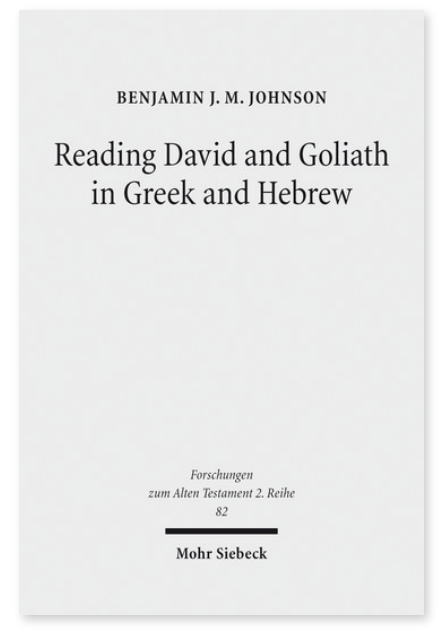

2015. XIV, 270 Seiten. FAT II 82

ISBN 978-3-16-154047-9

DOI 10.1628/978-3-16-154047-9

eBook PDF 104,00€

ISBN 978-3-16-154046-2

fadengeheftete Broschur 104,00€
Veröffentlicht auf Englisch.

Die Geschichte von David und Goliath existierte in der Antike in zwei verschiedenen literarischen Ausgaben, einer kurzen Version aus der griechischen Überlieferung des Codex Vaticanus (LXXB) und einer längeren Version, die in der hebräischen Überlieferung des MT zu finden sind. Benjamin J. M. Johnson schlägt vor, dass jede Version es Wert ist, für sich untersucht zu werden und bietet eine literarische Analyse der Erzählung von David und Goliath im griechischen Text des 1. Buch der Königtümer 16-18. Der Autor untersucht eine Methode des Lesens der Septuaginta, die anerkennt, dass es sich sowohl um ein eigenständiges Dokument als auch umeine Übersetzung des hebräischen Originals handelt. Indem er die SeptuagintaVersion der Erzählung über David und Goliath neu liest, hebt er die literarischen Unterschiede zwischen den beiden Versionen der Geschichte und die literarische Bedeutung der griechischen Übersetzung hervor.

Benjamin J. M. Johnson Born 1982; 2012 PhD in Theology, University of Durham; since 2012 Tutor in Biblical Interpretation at Wycliffe Hall, Oxford and member of the Faculty of Theology and Religion at Oxford University.
Jetzt bestellen:
https://mohrsiebeck.com/buch/reading-david-and-goliath-in-greek-and-hebrew-9783161540479?no_cache=1
order@mohrsiebeck.com
Telefon: +49 (0)7071-923-17
Telefax: +49 (0)7071-51104 